Chronic Obstructive Pulmonary Diseases:

Journal of the COPD Foundation

\author{
Original Research
}

\title{
Markers of Dental Health Correlate with Daily Respiratory Symptoms in COPD
}

Nathaniel T. Gaeckle, MD ${ }^{1}$ Brooke Heyman, MD $^{2}$ Andrew J. Criner, BS ${ }^{1}$ Gerard J. Criner, MD $^{1}$

\begin{abstract}
Background: Poor dental health occurs in patients with chronic obstructive pulmonary disease (COPD); some evidence suggests that it may correlate with lower forced expiratory volume in 1 second (FEV 1$)$ and 6-minute walk distance, and an increased rate of exacerbations. However, there is no data that examines how dental health may impact the daily respiratory symptoms that COPD patients experience. We prospectively studied indices of dental health and hygiene in patients with COPD and determined their impact on daily respiratory symptoms.

Methods: A total of 20 individuals with COPD (median [interquartile range (IQR)] \% FEV 37 [29-43]) and 10 healthy control individuals with no lung disease were recruited. Dental questionnaires, spirometry, and a dental examination were administered on their initial visit. COPD participants were given an electronic COPD daily diary to document peak expiratory flow and the presence and magnitude of daily breathlessness, cough, sputum production, and wheeze.

Results: Compared to healthy controls, COPD participants had less teeth (median 16.5 versus 28, $p=0.0001$ ), a trend to a higher plaque index (median 2.2 versus $1.7, p=0.15$ ), and worse oral health-related quality of life (median Oral Health Impact Profile score 12.0 versus 4.5, $p=0.02$ ). A greater number of teeth correlated with higher percentage of days with cough $(r=0.48, p<0.05)$ and wheeze $(r=0.47, p<0.05)$.

Conclusion: Individuals with severe COPD have poor oral hygiene and oral health-related quality of life. In the setting of poor dentition, a greater number of teeth correlates with more daily respiratory symptoms. More teeth may create a larger reservoir for inflammatory proteins and pathogenic bacteria to be aspirated into the airways.
\end{abstract}

Abbreviations: chronic obstructive pulmonary disease, COPD; forced expiratory volume in 1 second, FEV $\mathbf{1}$; interquartile range, IQR; National Health and Nutrition Survey, NHANES; plaque index, PI; forced vital capacity, FVC; oral health impact profile, OHIP; oral health impact profile summative score, OHIP-S; oral health impact profile weighted score, OHIP-W

Funding Support: This work was funded by a grant from AVISA Pharma, Inc.

Date of Acceptance: November 8, 2017

Citation: Gaeckle NT, Heyman B, Criner AJ, Criner GJ. Markers of dental health correlate with daily respiratory symptoms in COPD. Chronic Obstr Pulm Dis. 2018;5(2):97-105. doi: https://doi.org/10.15326/jcopdf.5.2.2017.0159

1 Department of Thoracic Medicine and Surgery, Lewis Katz School of Medicine at Temple University, Philadelphia, Pennsylvania

2 Department of Internal Medicine, Lewis Katz School of Medicine at Temple University, Philadelphia, Pennsylvania

\section{Address correspondence to:}

Nathaniel Gaeckle

Email: gaeckle@umn.edu

Phone: 612-805-8388

\section{Keywords:}

chronic obstructive pulmonary disease; COPD; dental; plaque index; oral health; respiratory symptoms

\begin{abstract}
Note: Some of the findings from this study were presented at the American Thoracic Society International Conference May 2017.
\end{abstract}

\section{Introduction}

Oral health has been shown to be an important factor in respiratory diseases such as pneumonia and chronic obstructive pulmonary disease (COPD). ${ }^{1}$ In the first large population studies looking at this connection, Scannapieco et $\mathrm{al}^{2,3}$ used National Health and Nutrition 
Examination Survey (NHANES) data to show that an oral hygiene index, which assesses dental plaque and calculus, and the mean attachment loss of the gingiva from the tooth both correlate with a diagnosis of COPD. Various other measures of dental health such as probing depth of dental pockets, gingival index, and plaque index (PI) are also associated with a diagnosis of $\mathrm{COPD}^{4,5,6}$ and correlate with disease severity assessed by forced expiratory volume in 1 second $\left(\mathrm{FEV}_{1}\right), 6$-minute walk distance, or COPD exacerbations. ${ }^{4,7,8}$

Improved oral hygiene may decrease adverse lower respiratory tract events. In a population of Japanese nursing home residents, regular oral care reduced rates of pneumonia. ${ }^{9}$ The use of chlorhexidine swabs in intubated and mechanically ventilated intensive care unit patients decreases the rate of ventilator associated pneumonia. ${ }^{10}$ In a small, randomized controlled study of 60 patients with COPD, regular tooth scaling and root planing decreased the rate of COPD exacerbations. ${ }^{11}$

COPD is a chronic illness hallmarked by daily respiratory symptoms such as breathlessness, wheeze, cough, and sputum production. ${ }^{12}$ These symptoms are caused by airflow obstruction and inflammation of the airways, and significantly impair quality of life. ${ }^{13,14}$ Barriers to adequate dental care are not well described in COPD individuals but could potentially include impaired mobility due to illness or use of oxygen, continued smoking, or access to dental insurance. Although poor dental health is associated with the diagnosis of COPD and some COPD-related health outcomes, the impact of dental health on daily respiratory symptoms that patients with COPD experience is unknown. We aimed to study the dental health and habits of a cohort of consecutive COPD individuals and test the hypothesis that poor dental health is associated with worse daily respiratory symptoms.

\section{Methods}

\section{Patient Population}

This was a prospective study at a single institution; all study procedures were approved by the Western Institutional Review Board. Participants were enrolled between February 2016 and December 2016. Healthy control individuals without lung disease and individuals with severe COPD were recruited for the study. Inclusion criteria were: (1) age $>40$, (2) spirometric findings in the COPD cohort of $\mathrm{FEV}_{1} /$ forced vital capacity $(\mathrm{FVC})<0.70$ with an $\mathrm{FEV}_{1}<50 \%$ predicted, and no airflow obstruction in the healthy control cohort, (3) at least a 10 pack-year smoking history in the COPD groups, and no current smoking in the healthy controls. Exclusion criteria were: (1) antibiotics in the last 4 weeks, (2) systemic steroid treatment for a COPD exacerbation within the last 4 weeks, (3) dental visit in the last 4 weeks, (4) taking $>20 \mathrm{mg}$ of prednisone or an equivalent dose of steroids on a daily basis, (5) history of solid organ transplant, (6) clinically significant bronchiectasis with more than $1 / 3$ cup sputum a day, (7) plan for major dental work in the next 3 months, (8) edentulous individuals, and (9) active malignancy other than skin cancer. Due to slow enrollment, the $\mathrm{FEV}_{1}$ criteria for COPD participants was expanded to $<80 \%$ predicted.

\section{Study Procedures}

At the first visit, participants completed questionnaires, a dental examination, and spirometry. COPD participants were instructed to use an electronic daily diary to report respiratory symptoms over the study period of approximately 60 days. A second visit was scheduled at the end of the study period where another questionnaire was given, and the dental examination was repeated.

\section{Oral Health Examination}

In addition to filling out questionnaires regarding dental hygiene habits, all participants completed the Oral Health Impact Profile - 14 (OHIP) on the first and second visit. ${ }^{15}$ This is a 14 -question patientcentered and symptom-based survey of how oral health affects quality of life. Seven different domains of oral health were surveyed: functional limitation, pain, psychological discomfort, physical disability, psychological disability, social disability and handicap. Each question was graded on a 5-point scale: 0 = never, 1 = hardly ever, 2 = occasionally, 3 = fairly often, 4 = very often. Higher scores signified worse quality of life. Each question is weighted and the total summative scores (OHIP-S) as well as total weighted scores (OHIP-W) were used.

Physical examination included counting the number of teeth and calculating the plaque index (PI). Participants were asked to not eat, brush their teeth, or use mouthwash the morning of the visit. All exams were performed by the same investigator (N.G). Plaque was identified using a Butler G-U-M red-cote dental disclosing tablet. Participants chewed on the tablet 
for 30 seconds, then expectorated the dye into the sink and washed out the oral cavity with water once. Dental plaque was stained pink. The PI is the average amount of plaque per tooth surface measured and was calculated using the Quigley-Hein method that was modified by Turesky et al in $1970 .^{16}$

The buccal and lingual surface of the tooth was examined, and a score given. A $0=$ no plaque, 1 = separate flecks of plaque, 2 = thin continuous band of plaque (up to $1 \mathrm{~mm}$ ) at the cervical margin of the tooth, $3=\mathrm{a}$ band of plaque wider than $1 \mathrm{~mm}$ but covering less than $1 / 3$ of the crown of the tooth, 4 = plaque covering at least $1 / 3$ but less than $2 / 3$ of the crown of the tooth, $5=$ plaque covering $2 / 3$ or more of the crown of the tooth. Each surface of the tooth score was added together and divided by total surfaces measured to calculate the PI.

\section{Daily COPD Diary}

We used a web-based Health Insurance Portability and Accountability-HIPPA-compliant electronic daily respiratory diary (HGE Health Care Solutions, Telford, Pennsylvania). Participants recorded symptoms through a smart phone app, computer interface or a tablet that was provided for the study. Every morning, participants were instructed to score their breathlessness (Borg scale), presence of sputum, cough, and wheeze and perform 3 peak flow maneuvers. The highest peak flow measure was recorded and used.

\section{Statistical Analysis}

Statistical analyses were performed using Stata 14.2 (StataCorp, College Station, Texas). Results are presented as median (interquartile range [IQR]). Wilcoxon rank sum testing was performed to compare groups. Percentages were compared using chi-squared testing. Dental indices were correlated with daily respiratory symptoms using Pearson's correlation coefficients using a significance level of $p<0.05$. Dental indices were further correlated with respiratory symptoms using linear regression.

\section{Results}

A total of 30 participants were recruited for the study (10 healthy controls, 20 individuals with COPD). There were no differences in age, sex, or body mass index between the healthy control and COPD participants (Table 1). COPD participants, as expected, had significantly worse lung function parameters. The COPD group consisted of 10 current smokers. Comparing former to current smokers with COPD, the former smokers had a higher median [IQR] age (64.5 [57-70] versus 56 [53-62], $P=0.02)$, and had more severe lung disease assessed by median [IQR] $\mathrm{FEV}_{1} \%$ predicted (30.5 [24-36] versus 39.5 [36-48], $P=0.05)$ and higher use of oxygen (50\% versus $0 \%$ ). Of note, only 2 COPD participants with an $\mathrm{FEV}_{1}>$ $50 \%$ were enrolled after the inclusion criteria were broadened to include participants with $\mathrm{FEV}_{1}<80 \%$. Overall, participants were in the study on average for 68.9 days with a daily symptom reporting compliance of $93.1 \%$ of days, for a total of 1158 patient days of daily symptom data. Two participants withdrew from the study; one after 9 days and the other after 3 days, both because they did not want to continue reporting daily symptoms (Figure 1). Given the limited daily symptom data collected from these 2 participants, their daily symptom data was not analyzed. One participant died during the study after reporting symptoms for 42 days; all her daily symptom data was included in the analysis.

\section{Dental Health and Habits}

Both COPD participants and controls had similar teeth brushing habits, with almost every participant brushing at least once a day (Figure 2). More of the healthy controls had a dental appointment closer to the time of enrollment than the COPD participants, suggesting more frequent dental visits in the control group. Frequency of flossing was heavily skewed with COPD participants rarely flossing as a part of their regular dental care. Most control participants flossed at least once a day. COPD participants had a dental history consisting of more dental infections, tooth extractions and higher prevalence of dentures (Table 2).

\section{Dental Indices}

Participants with COPD had less teeth, and higher OHIP scores indicating poor dental health. The average amount of plaque on the surface of a tooth, assessed by the PI, was higher in the COPD participants than in the healthy controls, but this did not reach statistical significance (Table 3). These relationships remained stable between the first and second visits. There was no difference between former and current smokers with COPD in median [IQR] number of teeth 


\section{Table 1. Baseline Characteristics}

\begin{tabular}{|c|c|c|c|}
\hline $\begin{array}{l}\text { Baseline } \\
\text { Characteristic }\end{array}$ & $\begin{array}{l}\text { Healthy Control } \\
\qquad(n=10)\end{array}$ & $\begin{array}{l}\text { COPD } \\
(n=20)\end{array}$ & $P$ value \\
\hline Age (years) & $54.5(50-60)$ & $60(56-68)$ & 0.15 \\
\hline Male - no. (\%) & $6(60)$ & $12(60)$ & 1.0 \\
\hline Body Mass Index $\left(\mathrm{kg} / \mathrm{m}^{2}\right)$ & $27.8(23.7-30.5)$ & $27.7(24.6-31.0)$ & 1.0 \\
\hline Black Race - no. (\%) & $3(30)$ & $15(75)$ & 0.02 \\
\hline \multicolumn{4}{|l|}{ Pulmonary Function Test: } \\
\hline FVC (\% pred) & $89(83-100)$ & $72(59-80.5)$ & 0.0005 \\
\hline FEV $_{1}$ (\% pred) & $89.5(82-102)$ & $36(27.5-42.5)$ & $<0.0001$ \\
\hline mMRC Dyspnea Scale & $0(0-0)$ & $3(2-3)$ & $<0.0001$ \\
\hline Current Smokers - no. (\%) & $0(0)$ & $10(50)$ & 0.007 \\
\hline Pack Years of Smoking & $0(0-1.5)$ & $30(16-54)$ & 0.0001 \\
\hline Oxygen Use - no. (\%) & 0 & $5(25)$ & 0 \\
\hline Average Exacerbations/year & N/A & 1.2 & $\mathrm{~N} / \mathrm{A}$ \\
\hline \multicolumn{4}{|c|}{$\begin{array}{l}\text { Data represented as median (IQR) unless indicated otherwise. Average exacerbations/ } \\
\text { year were tabulated in the year prior to enrollment. } \\
\text { FVC=forced vital capacity; FEV } 1 \text { =forced expiratory volume in } 1 \text { second; } \\
\text { mMRC=modified Medical Research Council dyspnea scale }\end{array}$} \\
\hline
\end{tabular}

\section{Figure 1. Trial Design}

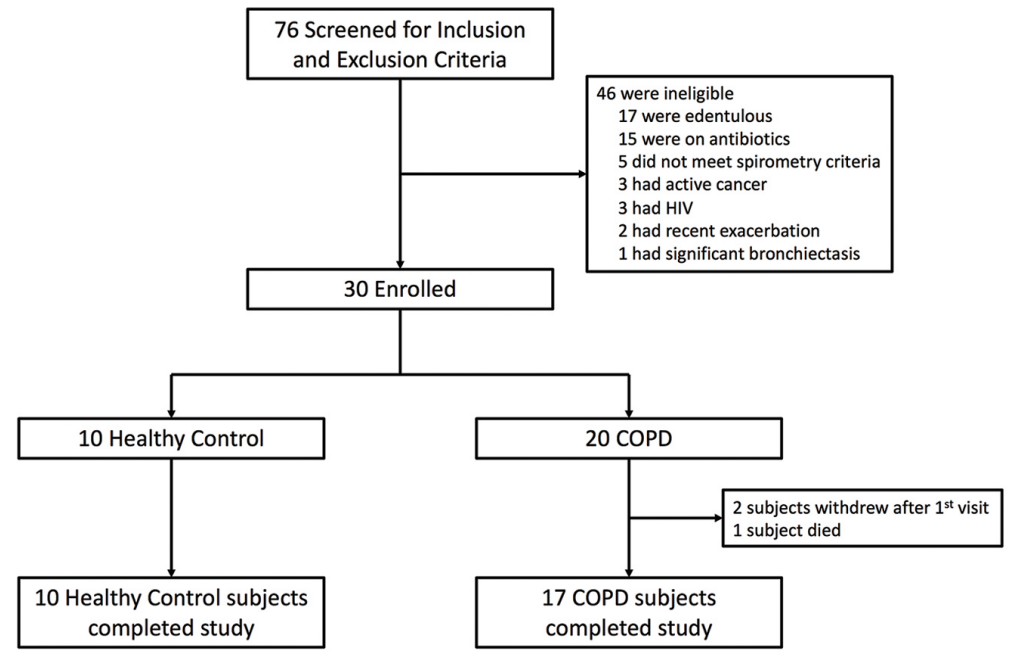

number of teeth still had a significant positive correlation with percentage of days with cough $(\beta=2.70, p=0.04)$ and wheeze $(\beta=2.65, p=0.01)$; $\mathrm{PI}$, however, did not significantly correlate with daily respiratory symptoms.

\section{Discussion}

In this prospective observational study, we found that compared to healthy control participants, participants with COPD have poor dental hygiene practices, a history of more dental infections, worse dental indices assessed by number of teeth and PI, and significantly worse oral health-related quality of life as assessed by OHIP-14. Additionally, after following daily respiratory symptoms in the COPD participants for approximately 2 months, we found that the greater number of teeth that a participant had positively correlated with more frequent daily respiratory symptoms such as sputum production, cough, and wheeze. Therefore, we found that in a population with very poor overall oral health, a greater number of teeth was associated with a greater daily burden of respiratory symptoms.

Our data on oral hygiene is consistent with prior reports of abnormal dental indices and suboptimal oral hygiene practices in the COPD population. Wang et $\mathrm{al}^{5}$ compared 306 participants with COPD to 328 control participants in a retrospective case-control study. They demonstrated that COPD participants had poor oral hygiene practices. In addition, they had less teeth and more plaque per tooth than controls. Other studies consistently show that COPD participants have fewer numbers of teeth than controls. ${ }^{2,7,17}$ Results of PI measurements have been variable, with some studies reporting a higher PI in COPD participants ${ }^{18,7,17}$ while others show no difference. ${ }^{4,6}$ Our results did not show a significantly higher PI in the COPD population ( $p=0.15)$, but given the fact that this was a small study $(n=30)$ it may have been underpowered to show this difference. Overall, our data on oral hygiene practices in COPD participants is consistent with what has been published and further emphasizes the poor oral health practices that are encountered in this population.

In line with the poor dental hygiene and indices in COPD participants, they experienced worse oral 
Figure 2. Oral Health Care Habits

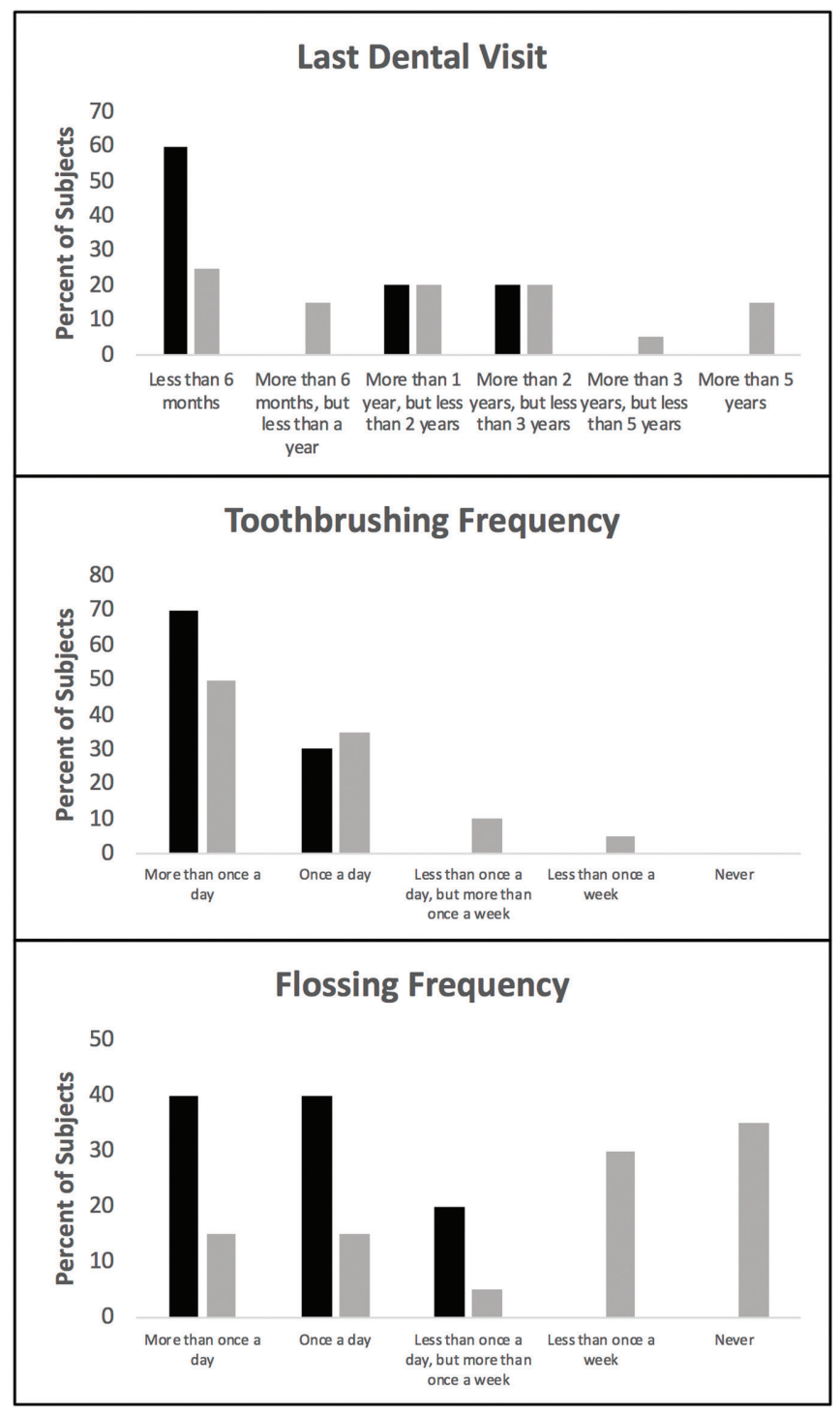

Black bars=healthy control, grey bars $=$ COPD participants.

Healthy control participants had a more recent visit to the dentist.

They also flossed more frequently than those with COPD

health-related quality of life assessed by the OHIP-14. To our knowledge, this questionnaire has only been reported in one prior study of COPD participants. ${ }^{19}$ In a group of 100 individuals with COPD, a worse OHIP score positively correlated with more reported oral problems, higher education level and smoking. A control group was not included in the data collection, and there was no mention of COPD disease severity or pulmonary-related symptoms. In our study, OHIP-14 scores were worse in COPD participants at both visits. Although higher OHIP scores correlated with more daily respiratory symptoms, the correlations were

\section{Table 2. Dental History}

\begin{tabular}{|l|c|c|c}
\hline & $\begin{array}{r}\text { Healthy } \\
\text { Control } \\
(\mathbf{n = 1 0})\end{array}$ & $\begin{array}{l}\text { COPD } \\
(\mathbf{n = 2 0})\end{array}$ & P value \\
\hline Mouthwash Use (\%) & 30 & 65 & 0.07 \\
\hline Dentures (\%) & 0 & 40 & 0.02 \\
\hline History of Tooth Abscess (\%) & 30 & 70 & 0.04 \\
\hline History of Tooth Extraction (\%) & 60 & 90 & 0.05 \\
\hline History of Root Canal (\%) & 70 & 55 & 0.43 \\
\hline Dental Crown (\%) & 60 & 40 & 0.30 \\
\hline Periodontitis (\%) & 10 & 15 & 0.70 \\
\hline Fillings (\%) & 90 & 75 & 0.33 \\
\hline
\end{tabular}

Table demonstrates percentage of participants in each group who self-reported to have the listed dental diagnosis or procedure performed. $P$ value calculated using chi-squared test.

weak. This relationship between oral health-related quality of life and respiratory symptoms needs to be studied in a larger population of COPD individuals.

The unique aspect of our study was the use of common daily respiratory symptoms as an outcome. We correlated number of teeth and the PI with daily symptoms that were documented in a daily electronic COPD symptom diary. There was no significant correlation between PI and respiratory symptoms. However, a greater number of teeth in participants with COPD significantly correlated with the presence of more cough and wheeze, even after adjustment for current smoking.

The microbiome of the lungs resembles the oral microbiome ${ }^{20}$ and the chronic microaspiration of saliva may play a role. ${ }^{21}$ Saliva bathes the surfaces of the mouth and its composition reflects the surrounding oral contact surfaces. Hence, more diseased teeth potentially provide a large reservoir of pathogenic bacteria, such as Haemophilus influenzae, ${ }^{22}$ and inflammatory proteins that provokes worsened respiratory symptoms when aspirated.

Chronic periodontitis is a common inflammatory disorder of the oral cavity and has previously been described in patients with COPD. ${ }^{23,24}$ Pockets of bacteria form between the tooth and gingiva, which adversely affects the supporting tooth structures and leads to tooth loss. Although there have been numerous bacteria identified in these inflammatory pockets with 16s rRNA sequencing, traditionally anaerobic bacteria, such as Porphyromonas gingivalis, Tannerella forsythia, and Treponema denticola are believed to drive the intense inflammatory response. ${ }^{23}$ Teeth are critical in developing a nidus for oral inflammation. 


\section{Table 3. Dental Indices Measured at Each Visit}

\begin{tabular}{l|r|r|r|r|r|r} 
& \multicolumn{3}{c}{ First Visit } & \multicolumn{3}{c}{ Second Visit } \\
\cline { 2 - 8 } & $\begin{array}{l}\text { Healthy Control } \\
(\mathrm{n}=10)\end{array}$ & $\begin{array}{c}\text { COPD } \\
(\mathrm{n}=20)\end{array}$ & $P$ value & $\begin{array}{c}\text { Healthy Control } \\
(\mathrm{n}=10)\end{array}$ & $\begin{array}{c}\text { COPD } \\
(\mathrm{n}=17)\end{array}$ & $P$ value \\
\hline Number of Teeth & $28(25-28)$ & $16.5(8.5-23.5)$ & 0.0001 & $28(25-28)$ & $21(8-23)$ & 0.0003 \\
\hline Plaque Index & $1.7(1.5-2.0)$ & $2.2(1.5-2.8)$ & 0.15 & $1.8(1.3-2.1)$ & $2.2(1.7-2.9)$ & 0.15 \\
\hline OHIP-S & $4.5(0-8)$ & $12(6-18.5)$ & 0.02 & $2(0-4)$ & $11(10-14)$ & 0.002 \\
\hline OHIP -w & $2.2(0-3.7)$ & $6.4(3.0-9.4)$ & 0.01 & $0.8(0-2.0)$ & $5.6(4.9-7.0)$ & 0.002 \\
\hline
\end{tabular}

Data represented as median (IQR). COPD participants have fewer teeth, and worse OHIP scores than control. Plaque index is worse in COPD participants but does not reach statistical significance. Dental indices remain stable between visits.

OHIP-S=oral health impact profile summative score; OHIP-W=oral health impact profile weighted score.

$P$ value calculated using Wilcoxon rank-sum testing.

\section{Table 4. Correlation of Dental Indices with Daily Respiratory Symptoms}

\begin{tabular}{|c|c|c|c|c|c|}
\hline $\begin{array}{l}\text { First Visit } \\
\text { Measurement }\end{array}$ & $\begin{array}{l}\text { Borg } \\
\text { Score }\end{array}$ & $\begin{array}{l}\text { Peak } \\
\text { Flow }\end{array}$ & $\begin{array}{l}\% \text { Days } \\
\text { with } \\
\text { Sputum }\end{array}$ & $\begin{array}{l}\% \text { Days } \\
\text { with } \\
\text { Cough }\end{array}$ & $\begin{array}{c}\% \text { Days } \\
\text { with } \\
\text { Wheeze }\end{array}$ \\
\hline Teeth & 0.25 & -0.10 & 0.39 & $0.51^{\mathrm{a}}$ & $0.51^{\mathrm{a}}$ \\
\hline PI & 0.24 & -0.02 & 0.05 & -0.07 & -0.12 \\
\hline OHIP-S & 0.37 & -0.23 & 0.09 & 0.22 & 0.07 \\
\hline OHIP-W & 0.36 & -0.20 & 0.09 & 0.17 & 0.04 \\
\hline \multicolumn{6}{|l|}{$\begin{array}{l}\text { Second Visit } \\
\text { Measurement }\end{array}$} \\
\hline Teeth & 0.22 & -0.17 & 0.48 & 0.47 & 0.46 \\
\hline PI & 0.12 & -0.01 & 0.08 & -0.04 & -0.19 \\
\hline OHIP-S & 0.45 & 0.09 & 0.38 & 0.19 & 0.34 \\
\hline OHIP-W & 0.47 & 0.09 & 0.41 & 0.18 & 0.32 \\
\hline
\end{tabular}

Pearson's correlation coefficients.

${ }^{a}$ represents statistical significance at a $P$ value $<0.05$.

$\mathrm{PI}=$ plaque index; OHIP-S=oral health impact profile

summative score; OHIP-W=oral health impact profile

After complete extraction of teeth in participants with chronic periodontitis, microbiome studies confirm that pro-inflammatory anaerobic bacteria markedly dissipate. ${ }^{25,26}$ Bacterial lipopolysaccharide, ${ }^{23}$ inflammatory proteins such as interleukin-1, interleukin- 6 and tumor necrosis factor- $\alpha,{ }^{27,28,29}$ as well as the inflammatory cell secretion of proteases, elastases, collagenases and matrix metalloproteinases are all involved in the disease process and could potentially be aspirated into the airways.

Our findings that a greater number of teeth correlate with worse respiratory symptoms contrasts to previous reports on COPD individuals. Liu et al used an arbitrary cutoff of 25 teeth and found that patients with $>2$ exacerbations per year had less than 25 teeth compared to infrequent exacerbators who had more

\section{Table 5. Number of Teeth as Independent Variable for Daily Symptoms}

\begin{tabular}{|c|c|c|c|}
\hline Symptom & $\beta$ & $\begin{array}{l}\text { Std } \\
\text { error }\end{array}$ & P value \\
\hline \multicolumn{4}{|l|}{ Univariate } \\
\hline Borg Score & 0.07 & 0.06 & 0.31 \\
\hline Peak Slow & -0.98 & 2.39 & 0.69 \\
\hline \% days with Sputum & 1.73 & 1.02 & 0.11 \\
\hline \% days with Cough & 2.68 & 1.13 & 0.03 \\
\hline \% days with Wheeze & 2.46 & 1.03 & 0.03 \\
\hline \multicolumn{4}{|c|}{ Adjusted for Current Smoking } \\
\hline Borg & 0.08 & 0.06 & 0.17 \\
\hline Peak Flow & -0.69 & 2.33 & 0.77 \\
\hline \% days with Sputum & 1.83 & 1.02 & 0.09 \\
\hline$\%$ days with Cough & 2.70 & 1.17 & 0.04 \\
\hline \% days with Wheeze & 2.65 & 0.93 & 0.01 \\
\hline
\end{tabular}

than 25 teeth. ${ }^{8}$ Unlike our cohort, less than $50 \%$ of their participants were Global initiative for chronic Obstructive Lung Disease stage 3 or $4 .{ }^{30}$ Additionally, they excluded individuals who had 10 or less teeth. In another study, where individuals were excluded if they had less than 15 teeth, ${ }^{7}$ the number of teeth inversely correlated with the modified Medical Research Council (mMRC) score. Both of these studies were retrospective case control studies with much larger sample sizes, but the fact that individuals were excluded based on number of teeth limits their findings. In our study, only edentulous individuals were excluded.

There are limitations worth noting in our study. It 
was a small, single center study and daily respiratory symptom data was collected over a relatively short period of time, which may not allow for a full assessment of symptoms or change in symptoms during an exacerbation. Although periodontal disease has strong correlations with COPD, we did not objectively measure periodontal disease in this study.

In conclusion, in this small observational study, we found that participants with severe COPD have poor dental hygiene practices, and a diminished oral healthrelated quality of life. Additionally, in the setting of poor dental health, the greater number of teeth that a participant had correlated with worsened daily respiratory symptoms such as cough and wheeze. These findings will need to be corroborated in larger studies, but they do support the idea of potentially targeting oral health to improve COPD outcomes in future trials.

\section{Acknowledgements}

Some of the findings from this study were presented at the American Thoracic Society International
Conference May 2017. Dr. Gaeckle contributed to study concept and design, data collection, analysis and interpretation of data, and drafting and revision of the manuscript. Dr. Heyman helped with interpretation of data, and revision of the manuscript. Andrew Criner helped with acquisition and storage of data. Dr. Gerard Criner served as the guarantor of the paper, contributed to study concept and design, analysis and interpretation of the data, critical revision of the manuscript for important intellectual content, and approval of the final manuscript.

\section{Declaration of Interest}

GJC reports grants from the National Institutes of Health and the Department of Defense, consulting from AstraZeneca, Boehringer Ingelheim, Holaira, Mereo, Third Pole, PneumRX, Pulmonx, Pearl, Amirall, CSA Medical, Broncus, AVISA Pharma, Inc, Lungpacer and GlaxoSmithKline; and contracted clinical trials from AstraZeneca, AVISA Pharma, Inc, Mereo, Boehringer Ingelheim, Broncus, GlaxoSmithKline, Lungpacer, Novartis, Pulmonx, PneumRx/BTG, and Yungjin. NTG, $\mathrm{BH}$, and $\mathrm{AJC}$ report no conflicts of interest. 


\section{References}

1. Azarpazhooh A, Leake JL. Systematic review of the association between respiratory diseases and oral health. $J$ Periodontol. 2006;77(9): 1465-1482.

doi: https://doi.org/10.1902/jop.2006.060010

2. Scannapieco F, Papandonatos G, Dunford R. Associations between oral conditions and respiratory disease in a national sample survey population. Ann Periodontol.1998;3(1):251-256. doi: https://doi.org/10.1902/annals.1998.3.1.251

3. Scannapieco FA, Ho AW. Potential associations between chronic respiratory disease and periodontal disease: Analysis of national health and nutrition examination survey III. $J$ Periodontol. 2001;72(1):50-56. doi: https://doi.org/10.1902/jop.2001.72.1.50

4. Peter KP, Mute BR, Doiphode SS, Bardapurkar SJ, Borkar MS, Raje DV. Association between periodontal disease and chronic obstructive pulmonary disease: A reality or just a dogma? J Periodontol. 2013;84(12):1717-1723.

doi: https://doi.org/10.1902/jop.2013.120347

5. Wang Z, Zhou X, Zhang J, et al. Periodontal health, oral health behaviours, and chronic obstructive pulmonary disease. J Clin Periodontol. 2009;36(9):750-755.

doi: https://doi.org/10.1111/j.1600-051X.2009.01448.x

6. Katancik JA, Kritchevsky S, Weyant RJ, et al. Periodontitis and airway obstruction. J Periodontol. 2005;76(11-s):2161-2167. doi: https://doi.org/10.1902/jop.2005.76.11-S.2161

7. Si Y, Fan H, Song Y, Zhou X, Zhang J, Wang Z. Association between periodontitis and chronic obstructive pulmonary disease in a Chinese population. J Periodontol. 2012;83(10):12881296. doi: https://doi.org/10.1902/jop.2012.110472

8. Liu Z, Zhang W, Zhang J, et al. Oral hygiene, periodontal health and chronic obstructive pulmonary disease exacerbations. $J$ Clin Periodontol. 2012;39(1):45-52.

doi: https://doi.org/10.1111/j.1600-051X.2011.01808.x

9. Yoneyama T, Yoshida M, Ohrui T, et al. Oral care reduces pneumonia in older patients in nursing homes. J Am Geriatr Soc. 2002;50(3):430-433.

doi: https://doi.org/10.1046/j.1532-5415.2002.50106.x

10. Shi Z, Xie H, Wang P, et al. Oral hygiene care for critically ill patients to prevent ventilator-associated pneumonia. Cochrane Library. 2013.

doi: https://doi.org/10.1002/14651858.CD008367.pub2

11. Zhou X, Han J, Liu Z, Song Y, Wang Z, Sun Z. Effects of periodontal treatment on lung function and exacerbation frequency in patients with chronic obstructive pulmonary disease and chronic periodontitis: A 2-year pilot randomized controlled trial. J Clin Periodontol. 2014;41(6):564-572. doi: https://doi.org/10.1111/jcpe.12247
12. Vogelmeier CF, Criner GJ, Martinez FJ, et al. Global strategy for the diagnosis, management and prevention of chronic obstructive lung disease 2017 report. Respirology. 2017;22(3):575601. doi: https://doi.org/10.1111/resp.13012

13. Deslee G, Burgel P, Escamilla R, et al. Impact of current cough on health-related quality of life in patients with COPD. Int $J$ Chron Obstr Pulmon Dis. 2016;11:2091. doi: https://doi.org/10.2147/COPD.S106883

14. Gruenberger J, Vietri J, Keininger DL, Mahler DA. Greater dyspnea is associated with lower health-related quality of life among european patients with COPD. Int J Chron Obstr Pulmon Dis. 2017;12:937.

doi: https://doi.org/10.2147/COPD.S123744

15. Slade GD. Derivation and validation of a short-form oral health impact profile. Community Dent Oral Epidemiol. 1997;25(4):284290. doi: https://doi.org/10.1111/j.1600-0528.1997.tb00941.x

16. Fischman SL. Current status of indices of plaque. J Clin Periodontol. 1986;13(5):371-374.

doi: https://doi.org/10.1111/j.1600-051X.1986.tb01475.x

17. Ledić K, Marinković S, Puhar I, et al. Periodontal disease increases risk for chronic obstructive pulmonary disease. Coll Antropol. 2013;37(3):937-942.

18. Prasanna SJ. Causal relationship between periodontitis and chronic obstructive pulmonary disease. J Indian Soc Periodontol. 2011;15(4):359-365.

doi: https://doi.org/10.4103/0972-124X.92570

19. Saltnes SS, Storhaug K, Borge CR, Enmarker I, Willumsen T. Oral health-related quality-of-life and mental health in individuals with chronic obstructive pulmonary disease (COPD). Acta Odontol Scand. 2015;73(1):14-20. doi: https://doi.org/10.3109/00016357.2014.935952

20. Charlson ES, Bittinger K, Haas AR, et al. Topographical continuity of bacterial populations in the healthy human respiratory tract. Am J Respir Crit Care Med. 2011;184(8):957963. doi: https://doi.org/10.1164/rccm.201104-0655OC

21. Bassis CM, Erb-Downward JR, Dickson RP, et al. Analysis of the upper respiratory tract microbiotas as the source of the lung and gastric microbiotas in healthy individuals. MBio. 2015;6(2):e00037-15. doi: https://doi.org/10.1128/mBio.00037-15

22. Hardie JM, Bowden GH. Bacterial flora of dental plaque. Br Med Bull. 1975;31(2):131-136. doi: https://doi.org/10.1093/oxfordjournals.bmb.a071266

23. Costalonga M, Herzberg MC. The oral microbiome and the immunobiology of periodontal disease and caries. Immunol Lett. 2014;162(2):22-38. doi: https://doi.org/10.1016/j.imlet.2014.08.017 
24. Eke PI, Dye B, Wei L, Thornton-Evans G, Genco R. Prevalence of periodontitis in adults in the united states: 2009 and 2010. $\mathrm{J}$ Dent Res. 2012;91(10):914-920. doi: https://doi.org/10.1177/0022034512457373

25. Waal Y, Winkel EG, Raangs GC, Vusse ML, Rossen JW, Winkelhoff AJ. Changes in oral microflora after full-mouth tooth extraction: A prospective cohort study. J Clin Periodontol. 2014;41(10):981-989. doi: https://doi.org/10.1111/jcpe.12297

26. Könöonen E, Asikainen S, Alaluusua S, et al. Are certain oral pathogens part of normal oral flora in denture-wearing edentulous subjects? Mol Oral Microbiol. 1991;6(2):119-122. doi: https://doi.org/10.1111/j.1399-302X.1991.tb00463.x

27. Boström L, Linder LE, Bergström J. Smoking and crevicular fluid levels of IL- 6 and TNF-a in periodontal disease. J Clin Periodontol. 1999;26(6):352-357.

doi: https://doi.org/10.1034/j.1600-051X.1999.260604.x

28. Graves D, Cochran D. The contribution of interleukin-1 and tumor necrosis factor to periodontal tissue destruction. $J$ Periodontol. 2003;74(3):391-401.

doi: https://doi.org/10.1902/jop.2003.74.3.391

29. Zhang D, Chen L, Li S, Gu Z, Yan J. Lipopolysaccharide (LPS) of porphyromonas gingivalis induces IL-1 $\beta$, TNF-a and IL-6 production by THP-1 cells in a way different from that of escherichia coli LPS. Innate Immun. 2008;14(2):99-107. doi: https://doi.org/10.1177/1753425907088244

30. Global Initiative for Chronic Obstructive Lung Disease (GOLD). Global Strategy for the Diagnosis, Management, and Prevention of Chronic Lung Disease (2017 Report). GOLD website. http:// goldcopd.org/ Published 2017. Accessed December 2017. 